\title{
Remediation of
}

\section{Chromium-Contaminated Soil Based} on Bacillus cereus WHX-1 Immobilized on Biochar: $\mathrm{Cr}(\mathrm{VI})$ Transformation and Functional Microbial Enrichment

OPEN ACCESS

Edited by:

Zhiling $\mathrm{Li}$,

Harbin Institute of Technology, China

Reviewed by:

Hong-yu Wang,

Zhejiang University of Technology,

China

Jing-Long Han,

Harbin Institute of Technology,

Shenzhen, China

Yilu Sun,

Research Center

for Eco-Environmental Sciences

(CAS), China

*Correspondence:

Zhiming Zhang

zhangzhiming@ouc.edu.cn

Specialty section:

This article was submitted to

Microbiotechnology,

a section of the journal

Frontiers in Microbiology

Received: 15 December 2020

Accepted: 10 February 2021

Published: 25 March 2021

Citation:

Chen Y, Wu H, Sun P, Liu J, Qiao S, Zhang D and Zhang Z (2021)

Remediation

of Chromium-Contaminated Soil

Based on Bacillus cereus WHX-1

Immobilized on Biochar: Cr(VI)

Transformation and Functional

Microbial Enrichment.

Front. Microbiol. 12:641913. doi: 10.3389/fmicb.2021.641913

\author{
Youyuan Chen ${ }^{1,2,3}$, Haixia Wu', Ping Sun', Jiaxin Liu', Shixuan Qiao', Dakuan Zhang \\ and Zhiming Zhang ${ }^{1,2,3 *}$
}

${ }^{1}$ College of Environmental Science and Engineering, Ocean University of China, Qingdao, China, ${ }^{2}$ Key Lab of Marine Environment and Ecology, Ministry of Education, Ocean University of China, Qingdao, China, ${ }^{3}$ Shandong Provincial Key Laboratory of Marine Environment and Geological Engineering, Ocean University of China, Qingdao, China

Microorganisms are applied to remediate chromium (Cr)-contaminated soil extensively. Nevertheless, the microbial loss and growth inhibition in the soil environment restrain the application of this technology. In this study, a $\mathrm{Cr}(\mathrm{VI})$-reducing strain named Bacillus cereus WHX-1 was screened, and the microbial aggregates system was established via immobilizing the strain on Enteromorpha prolifera biochar to enhance the $\mathrm{Cr}(\mathrm{VI})$ reducing activity of this strain. The mechanism of the system on $\mathrm{Cr}(\mathrm{VI})$ transformation in Cr-contaminated soil was illuminated. Pot experiments indicated that the microbial aggregates system improved the physicochemical characteristics of Cr-contaminated soil obviously by increasing organic carbon content and cation exchange capacity, as well as decreasing redox potential and bulk density of soil. Moreover, 94.22\% of $\mathrm{Cr}(\mathrm{VI})$ was transformed into $\mathrm{Cr}(\mathrm{III})$ in the pot, and the content of residue fraction Cr increased by 63.38\% compared with control check (CK). Correspondingly, the physiological property of Ryegrass planted on the Cr-contaminated soil was improved markedly and the main $\mathrm{Cr}(\mathrm{VI})$-reducing microbes, Bacillus spp., were enriched in the soil with a relative abundance of $28.43 \%$ in the microbial aggregates system. Considering more active sites of biochar for microbial aggregation, it was inferred that $B$. cereus WHX-1 could be immobilized by $E$. prolifera biochar, and more $\mathrm{Cr}(\mathrm{VI})$ was transformed into residue fraction. Cr stress was decreased and the growth of plants was enhanced. This study would provide a new perspective for Cr-contaminated soil remediation.

Keywords: $\mathrm{Cr}(\mathrm{VI})$-reducing bacteria, biochar, immobilization, $\mathrm{Cr}(\mathrm{VI})$ transformation, stress remission

\section{INTRODUCTION}

$\mathrm{Cr}$ is the main heavy metal in polluted soil with two speciation of $\mathrm{Cr}(\mathrm{VI})$ and $\mathrm{Cr}(\mathrm{III})$. The toxicity of $\mathrm{Cr}(\mathrm{VI})$ is about 300 times that of $\mathrm{Cr}(\mathrm{III})$. More $\mathrm{Cr}(\mathrm{VI})$ could diffuse through biofilm with the form of $\mathrm{CrO}_{4}{ }^{2-}$ or $\mathrm{HCrO}_{4}{ }^{-}$, leading to oxidization of biomolecules, and biological activity decreased significantly. Lots of technologies for $\mathrm{Cr}(\mathrm{VI})$-contaminated soil 
remediation have been implemented (Yin et al., 2019; Xia et al., 2021). Among them, the biological technology was applied extensively for its simple process, low cost, and less secondary pollution. A variety of microorganisms, e.g., Bacillus, have been selected for Cr(VI) removal (Zeng et al., 2019). Nevertheless, the microbial loss and growth inhibition in the soil environment limit the performance of this technology. Thus, microbial immobilization technology should be implanted for the sake of reducing microbial loss and improving biodegradation efficiency (Luo et al., 2015; Tan et al., 2020b).

The choice of carrier material is an important factor for microbial fixation (Rikmann et al., 2016), and activated carbon, peat, sodium alginate, and biochar are common carriers as described by previous studies (Luo et al., 2015; Abu Talha et al., 2018). Among them, biochar is applied extensively for its simple preparation, low cost, as well as promotion of microbial attachment, metabolic activities, and tolerance for adverse environments (Lee et al., 2016; Xia et al., 2016; Siedt et al., 2021). Biochar has the ability to improve physicochemical properties of soil, including cation exchange capacity (CEC), organic carbon content (OC), and bulk density. Thus, $\mathrm{Cr}$ stress for microbes would be remitted.

Biochar could be produced by several materials (Hale et al., 2015). Regulation of surface characteristics of biochar, including functional groups, elements composition, and other factors were the main bottleneck for the biochar application. The raw materials for the preparation of biochar determined the surface characteristics of biochar. As described by previous studies, when sludge, biogas residue, and pine needles were the main raw materials of biochar, lots of heavy metals, polycyclic aromatics, and free radicals appeared on the surface of biochar and have toxic effects on algae, Rhizoctonia, and Streptomyces (Yang et al., 2019; Li J. et al., 2019). In comparison, studies of biochar derived from Chlorella vulgaris contained higher content of $\mathrm{P}$, $\mathrm{K}, \mathrm{Mg}$, and $\mathrm{Ca}$, compared with that derived from lignocellulosic biomass, suggesting the excellent perspective of algae as raw material for biochar (Wang et al., 2013). It would be necessary to investigate the effect of raw materials for the characteristics of biochar. Recent studies indicated that biochar made from algae contained hydroxyl, ketone, phenolic, aldehyde, carboxyl, and other polar functional groups had abundant binding sites for heavy metal adsorption (Lehmann et al., 2011; Nautiyal et al., 2016). Moreover, algal biochar had the advantages of adequate alkalinity and sufficient extractable inorganic nutrients; therefore, the biochar could provide favorable survival conditions for microbes (Abdelhafez et al., 2014; Sun et al., 2016; Yu et al., 2017), Nevertheless, adsorption capacity of the biochar is lower than that of lignin biochar, which limited the application of the biochar (Zhou et al., 2019). As described by Abu Talha et al. (2018), the attachment of $\mathrm{Cr}(\mathrm{VI})$-reducing bacteria could decrease the defects of low adsorption capacity and easy saturation of biochar and improve the reuse capacity of biochar. Therefore, it is necessary to explore the interaction between algal biochar and microbes for the remediation of $\mathrm{Cr}(\mathrm{VI})$-contaminated soil. Ryegrass is not only a predominant forage species grown in temperate regions but also a kind of turfgrass grown on dry and salty lands (Wu et al., 2005). According to Chen et al. (2017), Ryegrass could survive in the salt-alkali estuary region (salinity
0-20\%, pH 7-9) of Licun River, Qingdao, China. Moreover, it was applied globally for heavy metal bioaccumulation reported in previous studies (Healy et al., 2016; Mitchell et al., 2018).

The main objectives of the paper were to (1) screen $\mathrm{Cr}(\mathrm{VI})$ reducing bacteria from the Cr-contaminated soil and prepare biochar-based Cr-reducing microbial aggregation, (2) document the effect the microbial aggregates for $\mathrm{Cr}$ transformation and physicochemical property improvement of Cr-contaminated soil, and (3) illuminate the mechanism of the microbial aggregates for soil remediation in the aspect of $\mathrm{Cr}$ fraction and functional microbial enrichment.

\section{MATERIALS AND METHODS}

\section{Isolation and Identification of Cr(VI)-Reducing Bacteria}

The bacteria were isolated from the $\mathrm{Cr}$-contaminated soil samples from Qingdao Hongxing Chemical Factory, and the main products of this factory were inorganic salt. The dilution plate technique method was applied for the strain isolation. The total $\mathrm{Cr}[\mathrm{Cr}(\mathrm{T})]$ content of the experimental soil is $1205.06 \mathrm{mg} \cdot \mathrm{kg}^{-1}$, and the $\mathrm{Cr}(\mathrm{VI})$ content is $109.83 \mathrm{mg} \cdot \mathrm{kg}^{-1}$. Ten grams of the soil sample was transferred to a conical flask containing $100 \mathrm{ml}$ of sterile distilled water and shaken at room temperature for $30 \mathrm{~min}$ at $140 \mathrm{rpm}$. The homogenized soil sample was serially diluted and spread on Luria Bertani (LB) agar plate containing $100 \mathrm{mg} \cdot \mathrm{L}^{-1}$ $\mathrm{Cr}\left(\mathrm{r} \mathrm{pla}_{2} \mathrm{Cr}_{2} \mathrm{O}_{7}\right)$ and then the culture plates were incubated at $30 \pm 2{ }^{\circ} \mathrm{C}$ for $3-5$ days. The isolated strain with the function of $\mathrm{Cr}(\mathrm{VI})$ reduction was identified by $16 \mathrm{~S}$ rRNA gene sequencing and selected for the subsequent studies.

\section{Biochar Preparation}

Enteromorpha prolifera was purchased from Ocean University of China Biotechnology Co., Ltd. (Qingdao, China). Biochar samples used in this study were produced by slow pyrolysis at 400ishased 0 min under a limiting oxygen atmosphere. After natural cooling and washing by distilled water, the biochar was placed in oven at $60^{\circ} \mathrm{C}$ and then dried for preparation.

\section{The Establishment of Cr-Reduction Microbial Aggregates System}

E. prolifera biochar (1 g) was added into $50 \mathrm{ml}$ of LB liquid medium and sterilized at $121^{\circ} \mathrm{C}$ for $20 \mathrm{~min}$, and then $20 \mathrm{ml}(10 \%$ $\mathrm{v} / \mathrm{v}$ ) of strain samples was inoculated in the mixture and shaken at $140 \mathrm{rpm}$ for $24 \mathrm{~h}$ in $30^{\circ} \mathrm{C}$ for the sake of biofilm formation on the biochar surface. After that, the inoculated mixture was centrifuged at $5000 \mathrm{rpm}$ for $5 \mathrm{~min}$ and discarded the supernatant. The precipitate was washed three times with Tris- $\mathrm{HCl}(\mathrm{pH} 9)$ to remove the unfixed bacteria on the surface. The biochar attached with functional strain was established, and the Cr-reduction microbial aggregates system was named as WBC in this study.

\section{Pot Experiment}

To simulate the effect of adding microbial aggregates on the removal of $\mathrm{Cr}(\mathrm{VI})$ and plant growth in the soil, a pot experiment was carried out. Before planting, the strain 
TABLE 1 | Pot experiment soil treatment.

\begin{tabular}{lcccc}
\hline Group & $\mathbf{C r}(\mathbf{V I}) \mathbf{( m g \cdot \mathbf { k g } ^ { - \mathbf { 1 } } )}$ & Bacteria (ml) & Biochar $(\mathbf{g})$ & Inocula (g) \\
\hline CK- & 0.00 & - & - & - \\
CK & 50.00 & - & - & - \\
W & 50.00 & 20 & - & - \\
BC & 50.00 & - & 20 & - \\
W+BC & 50.00 & 20 & 20 & - \\
WBC & 50.00 & - & - & 20 \\
\hline
\end{tabular}

was isolated from Cr-contaminated soil and cultured in LB liquid medium to static conditions and then centrifuged at $5,000 \mathrm{rpm}$ for $5 \mathrm{~min}$, the supernatant was discarded, and the precipitate was rinsed twice with sterile $0.85 \% \mathrm{NaCl}$. To simulate the Cr-contaminated soil, soil used in this experiment was contaminated with $\mathrm{K}_{2} \mathrm{CrO}_{4}$ for a week to obtain a concentration of $50 \mathrm{mg} \cdot \mathrm{kg}^{-1} \mathrm{Cr}(\mathrm{VI})$. The groups with different treatments are shown in Table 1: $\mathrm{CK}^{-}$(without $\mathrm{Cr}$ contaminated soil), CK (Cr-contaminated soil), W (bacteria), BC (biochar), W+BC (bacteria and biochar), and WBC (microbial aggregates system). Except for the $\mathrm{CK}^{-}$, all other experimental groups had the same $\mathrm{Cr}(\mathrm{VI})$ content. Soil moisture was maintained around the maximum water holding capacity by applying irrigation (Table 1) and Ryegrass were selected as the representative plants in this study. The Ryegrass seeds were washed with $\mathrm{H}_{2} \mathrm{O}_{2}(3 \%$, v/v) and then deionized water. Then, the seeds were sown in the pots. After germination, equal numbers of healthy and uniform seedlings were kept in each pot. The pots were kept in the greenhouse with a day/night photoperiod of $14 / 10 \mathrm{~h}(10,000 \mathrm{lux})$ and a temperature of $28 / 22^{\circ} \mathrm{C}$ ( $\mathrm{Li} \mathrm{J}$. et al., 2019). After 30 days of culture, the characteristics of $\mathrm{Cr}$ in the soil were analyzed. Furthermore, physicochemical properties of soil $[\mathrm{pH}$, oxidation-reduction potential (ORP), CEC, OC, and bulk density], plant growth, and microbial community in the soil were analyzed.

\section{Analysis Methods \\ Measurement of Soil $\mathrm{Cr}$}

The $\mathrm{Cr}(\mathrm{T})$ content was determined by the spectrophotometric method and the $\mathrm{Cr}(\mathrm{VI})$ content was estimated by the diphenylcarbazide (DPC) method. The $\mathrm{Cr}$ (III) content in the sample was calculated by subtracting the $\mathrm{Cr}(\mathrm{VI})$ content from the $\mathrm{Cr}(\mathrm{T})$ content. The qualification of $\mathrm{Cr}$ (III) was mainly based on the subtraction method by most researchers (Wu et al., 2016; Xu Z. et al., 2019; Aparicio et al., 2021).

\section{Soil and Plant Characteristics}

Soil $\mathrm{pH}$ was measured with a $\mathrm{pH}$ meter. ORP was measured with the electric potential method. CEC was measured with the barium chloride exchange method. Organic carbon content was measured with potassium dichromate spectrophotometry. Bulk density was measured with the cutting ring method.

The bioconcentration factor (BCF), root concentration factor (RCF), and translocation factor (TF) were key characteristics that could explore the influence of the microbial aggregate system on the transportation and accumulation capacity of Ryegrass. The
BCF, RCF, and TF for Cr(VI) were determined according to a method described by Sidhu et al. (2017). The BCF, RCF, and TF were calculated as follows:

$$
\begin{gathered}
\mathrm{BCF}=\frac{C_{p}}{C_{s}} \\
\mathrm{RCF}=\frac{C_{r}}{C_{s}} \\
\mathrm{TF}=\frac{C_{s}}{C_{r}}
\end{gathered}
$$

where $\mathrm{C}_{p}(\mathrm{mg} / \mathrm{kg})$ was the concentration in the stems and shoots, $\mathrm{C}_{s}(\mathrm{mg} / \mathrm{kg})$ was the concentration in the soil, $\mathrm{C}_{r}(\mathrm{mg} / \mathrm{kg})$ was the concentration in the roots.

\section{Analysis of Biochar Surface}

The surface topographies of biochar were quantified by Image J based on the results of SEM according to Tsui et al. (2018). Briefly, a plugin called SurfCharJ was processed to quantify surface characterization before the image type set as 32-bit. Several surface roughness parameters, i.e., arithmetic mean deviation $\left(R_{a}\right)$ and root-mean-square deviation $\left(R_{q}\right)$, were fitted. The valleys in the granules were visualized by interactive $3 \mathrm{D}$ surface plots generated with a plugin compatible with ImageJ (Prathibha et al., 2011; Chen et al., 2021).

The functional groups on the surface of biochar were analyzed by Fourier infrared spectrometer. The E. prolifera biochar was mixed with $\mathrm{KBr}$ (spectrally pure) powder with a ratio of 1:10, ground with an agate mortar, and then pressed into tablets. Using a Fourier infrared spectrometer (BRUKER TENSOR 27) with a resolution of $4 \mathrm{~cm}^{-1}$, a scanning area of $400-4,000 \mathrm{~cm}^{-1}$ was used to determine the surface functional groups of the E. prolifera biochar.

\section{Microbial Community Analysis}

The molecular characterization of the isolated bacteria strain was done by $16 \mathrm{~S}$ rRNA gene sequencing. The nearly fulllength $16 \mathrm{~S}$ rRNA gene was amplified by PCR using universal primers 27F (5'-AGAGTTTGATCCTGGCTCAG-3') and 1492R (5'-GGTTACCTTGTTACGACTT- $3^{\prime}$ ), and the PCR products were sequenced by RuiBiotech Ltd. (Qingdao, China). The nucleotide sequences of the 16S rRNA gene were compared with available sequences using the Basic Local Alignment Search Tool (BLAST).

The identification of Cr-reducing strain and analysis of microbial community in the soil were operated by $16 \mathrm{~S}$ rRNA gene sequencing. The genomic DNA of the sample was extracted following the protocol of the Power Soil DNA extraction kit (MO BIO Laboratories Inc.). The total DNA extracted from the sample was used as a template, and the V3V4 region of the bacterial $16 \mathrm{~S}$ rRNA was amplified with the primers (338F $5^{\prime}$-ACTCCTACGGGAGGCAGCAG$3^{\prime} ; \quad$ 806R $\quad 5^{\prime}$-GGACTACHVGGGTWTCTAAT-3'). All reactions were carried out in $25 \mu \mathrm{l}$ (total volume) mixtures containing approximately $25 \mathrm{ng}$ of genomic DNA extract, 12.5 $\mu$ l of PCR Premix, $2.5 \mu \mathrm{l}$ of each primer, and PCRgrade water to adjust the whole volume. PCR reaction 


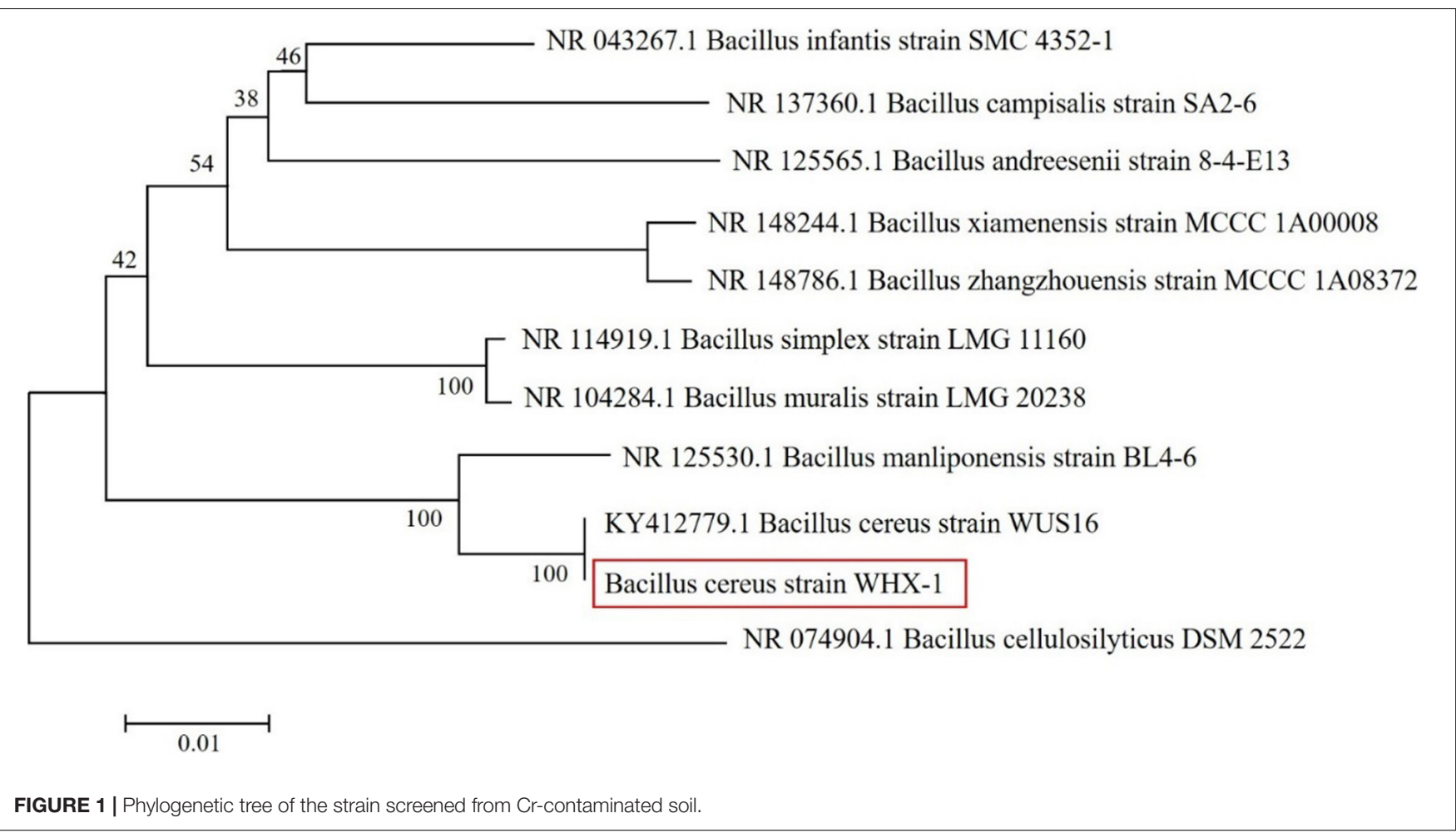

was performed in a Master cycler gradient thermocycler (Eppendorf, Hamburg, Germany) set under the following conditions: Initial denaturation at $98^{\circ} \mathrm{C}$ for $30 \mathrm{~s} ; 35$ cycles of denaturation at $98^{\circ} \mathrm{C}$ for $10 \mathrm{~s}$, annealing at $53^{\circ} \mathrm{C}$ for $30 \mathrm{~s}$, and extension at $72^{\circ} \mathrm{C}$ for $45 \mathrm{~s}$; and then final extension at $72^{\circ} \mathrm{C}$ for $10 \mathrm{~min}$. The PCR products of sample are sequencing by the Illumina MiSeq platform (PE300, CA, United States).

\section{Statistical Analysis}

Each experiment was carried out in triplicate. Statistical analysis was performed using the statistical software SPSS version 20.0. The means of three replicates were subjected to one-way analysis of variance using Tukey's HSD (honest significant difference) test at a significance level of $P<0.05$.

\section{RESULTS AND DISCUSSION}

\section{Identification of Cr-Reduction Strain}

The strain was isolated from $\mathrm{Cr}$-contaminated soil samples and identified by $16 \mathrm{~S}$ rDNA genome sequencing. According to the phylogenetic tree, the strain shared close genetic similarity with other identified Bacillus spp., especially Bacillus cereus strain WUS16 (Figure 1), and the strain was named Bacillus cereus WHX-1 in this study. The degrading curve of $\mathrm{Cr}(\mathrm{VI})$ by $B$. cereus WHX-1 conformed to firstorder kinetics equation and is shown in Supplementary Figure S5.

\section{Transformation of Cr With Microbial Aggregates Addition in Soil}

A pot experiment was conducted to explore the effect of the microbial aggregates containing strain (B. cereus WHX-1) on $\mathrm{Cr}$ in soil, including the transformation of $\mathrm{Cr}(\mathrm{VI})$ and the change of $\mathrm{Cr}$ fraction. The soil was full of electron donors, including plant roots and root-related fungi, as well as lowmolecular-weight organic acids (LMWOA) produced by humus, rhizosphere bacteria, etc., which have a certain reduction and adsorption effect on $\mathrm{Cr}(\mathrm{VI})$. The soil used in this experiment is unsterilized $\mathrm{Cr}(\mathrm{VI})$ contaminated soil. The decrease of $\mathrm{Cr}(\mathrm{VI})$ concentration may be caused by various factors such as chemistry and biology. LMWOA such as citric acid and tartaric acid contained reduction functional groups, which could be used as a weak reducing agent to reduce $\mathrm{Cr}(\mathrm{VI})$ (Xu Z. et al., 2019). In addition, the soil was enriched with bacterial communities, and some species had the ability for $\mathrm{Cr}(\mathrm{VI})$ reduction, such as Oceanobacillus, Bacillus, Pseudomonas (Li M. et al., 2019; Zeng et al., 2019; Yao et al., 2020), etc., and $\mathrm{Cr}(\mathrm{VI})$ would be reduced directly or indirectly by these microbes. As shown in Figure 2A, the content of $\mathrm{Cr}(\mathrm{VI})$ in the group with microbial aggregates addition (WBC) was $2.89 \mathrm{mg} \cdot \mathrm{kg}^{-1}$, which was the lowest in all treatment, while the soil added with only the strains contained a higher $\mathrm{Cr}(\mathrm{VI})$ content of $9.65 \mathrm{mg} \cdot \mathrm{kg}^{-1}$. The results indicated that WHX-1 could not adapt to the change of soil environment alone during a short process, and the function of the strain could not work fully. Nevertheless, biochar was the common electron donor or electron shuttle agent for $\mathrm{Cr}(\mathrm{VI})$ reductions described by Xu X. Y. et al. (2019). When the strains were attached on the biochar, and the microbial aggregates system was established, biochar 

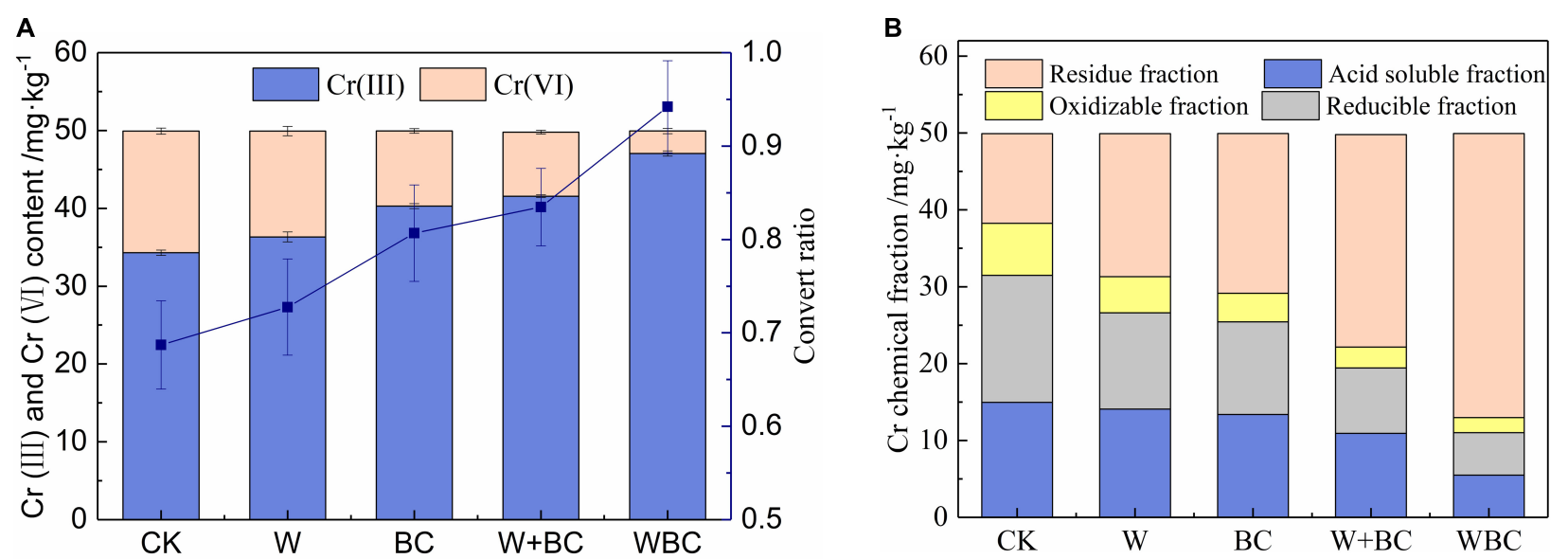

FIGURE 2 | The speciation of $\mathrm{Cr}$ in soil with different remediation methods. (A) Speciation and convert ratio. (B) Chemical fraction.
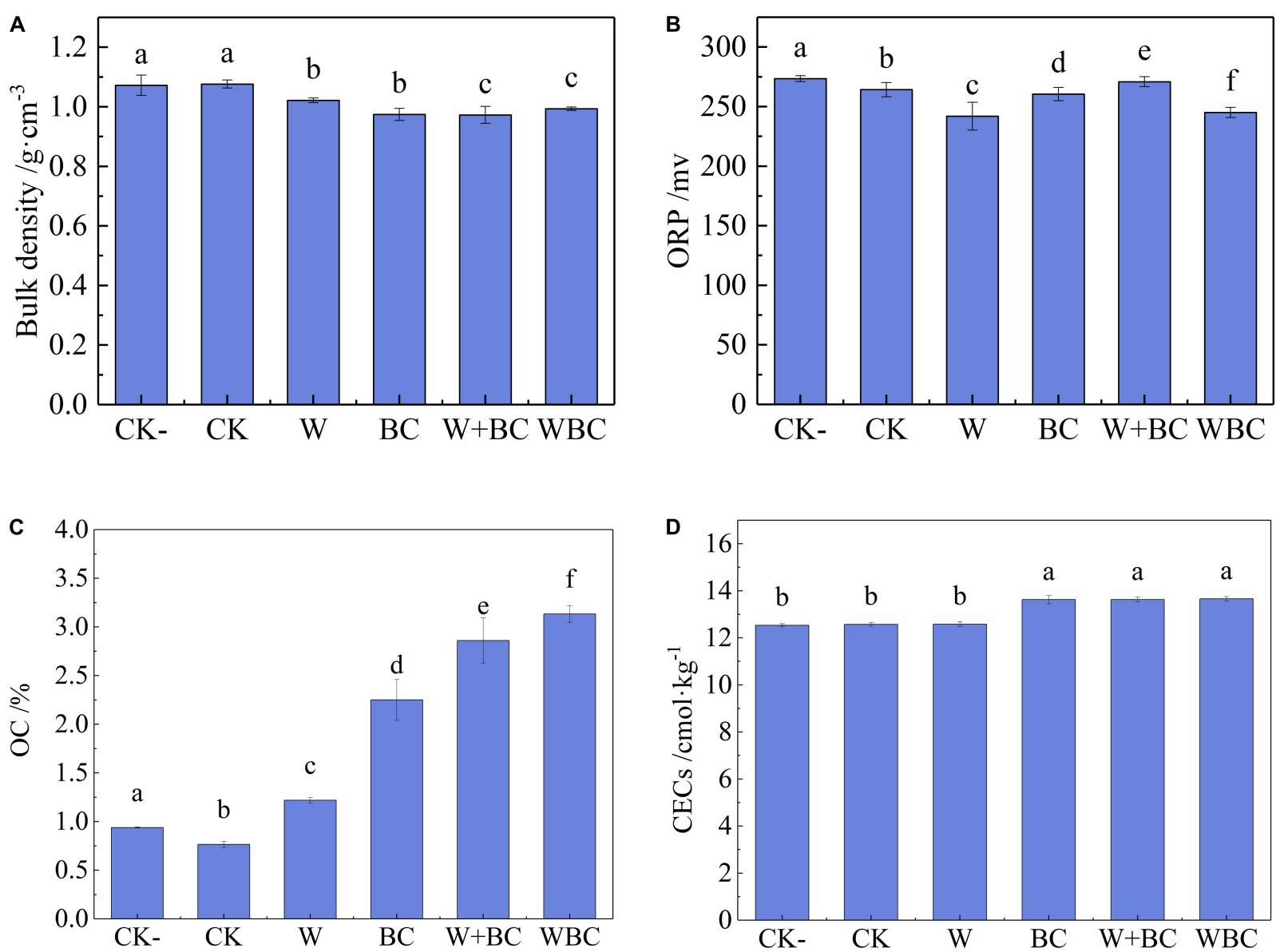

FIGURE 3 | Soil characteristics with different remediation methods. (A) Bulk density. (B) Redox potential. (C) Organic carbon. (D) Cation exchange capacity. Error bars represent the standard deviation of the mean $(n=3)$. Values in a given column followed by the same letter are not significantly different $(P<0.05)$ using Tukey test.

provides habitat for microorganisms, protects the strain WHX1 from the stress of environmental factors, and increased the survival rate, leading to uniform distribution of the strain in the soil. Meanwhile, the adsorption of biochar for $\mathrm{Cr}(\mathrm{VI})$ in the soil enhanced the interaction between the strain and $\mathrm{Cr}(\mathrm{VI})$, and the transformation rate of $\mathrm{Cr}(\mathrm{C})$ to $\mathrm{Cr}$ (to Crnd the transformatAfter 
Cr(III) was formed, it was easy to be precipitated or fast combined with the negatively charged organic matter and colloid in the soil, and the mobility is greatly reduced. Studies have shown that cocoa plants could tolerate $100-600 \mathrm{mg} / \mathrm{kg}$ of $\mathrm{Cr}$ (III). With the increase of $\mathrm{Cr}$ (III) concentration, plants alleviate the negative effects through root accumulation and secretion of antioxidant enzymes (Do Nascimento et al., 2018). In addition, pH of most biochar was alkaline and neutral, and the addition of biochar as a bacterial agent carrier could maintain the $\mathrm{pH}$ of soil at high level to avoid $\mathrm{Cr}$ (III) dissolution, and the mobility of $\mathrm{Cr}$ would be restrained (Xu T. et al., 2020).

Cr with different fraction showed varied toxicity for biology, and the effect of the microbial aggregates system on the fraction of $\mathrm{Cr}$ in soil is shown in Figure 2B. Compared with $\mathrm{CK}$, the content of residue fraction of $\mathrm{Cr}$ in WBC increased sharply with the value of $36.95 \mathrm{mg} \cdot \mathrm{kg}^{-1}$, while the sum of acid-soluble, oxidizable, and reducible fraction of $\mathrm{Cr}$ was lowest with the value of $13.05 \mathrm{mg} \cdot \mathrm{kg}^{-1}$. As described by previous studies (Chen et al., 2008; Zhang et al., 2017), the bioavailability and ecotoxicity of heavy metals were mainly based on the fraction in soil. The acid-soluble and exchangeable fraction indicated the higher bioavailability of $\mathrm{Cr}$ (Yuan et al., 2011), while the oxidizable and residual fraction of $\mathrm{Cr}$ were more stable and difficult to accumulate in plants or enriched through food chain; thus, the toxic effect of $\mathrm{Cr}$ could be reduced (Tan et al., 2020a). It was concluded that the microbial aggregates system in this study could effectively decrease bioavailability of $\mathrm{Cr}$ and enhance the remediation of Cr-contaminated soil.
TABLE 2 | Effect of Ryegrass on Cr enrichment coefficient and transfer coefficient under the action of biochar-based Cr-reducing bacteria.

\begin{tabular}{llll}
\hline Treatment & \multicolumn{3}{c}{ Estimators } \\
\cline { 2 - 4 } & (TF) & (BCF) & Root concentration factor (RCF) \\
\hline CK & 0.23 & 0.04 & 0.17 \\
W & 0.24 & 0.04 & 0.16 \\
BC & 0.16 & 0.02 & 0.12 \\
W+BC & 0.15 & 0.02 & 0.11 \\
WBC & 0.13 & 0.01 & 0.09 \\
\hline
\end{tabular}

\section{Characteristics of Soil Remediated by the Microbial Aggregates System}

The lower content of bioavailable $\mathrm{Cr}$ in soil was achieved via the remediation of the microbial aggregates system in this study, and the soil characteristics would be improved correspondingly. The $\mathrm{pH}$ of each group was similar at the range of 7.1-7.2; the result did not show significant difference, and the relevant graph can be seen in Supplementary Figure S4. As shown in Figure 3, bulk density and CEC of soil were at the range of $0.97-1.07 \mathrm{~g} \cdot \mathrm{cm}^{-3}$ and $12.53-13.66 \mathrm{cmol} \cdot \mathrm{kg}^{-1}$, respectively. The two characteristics in each group were similar and did not show significant change. So, bulk density and CEC of soil were not the main characteristics affected by the addition of the microbial aggregates system when compared with OC and ORP according to the results of this study. As described by previous studies, organic carbon could

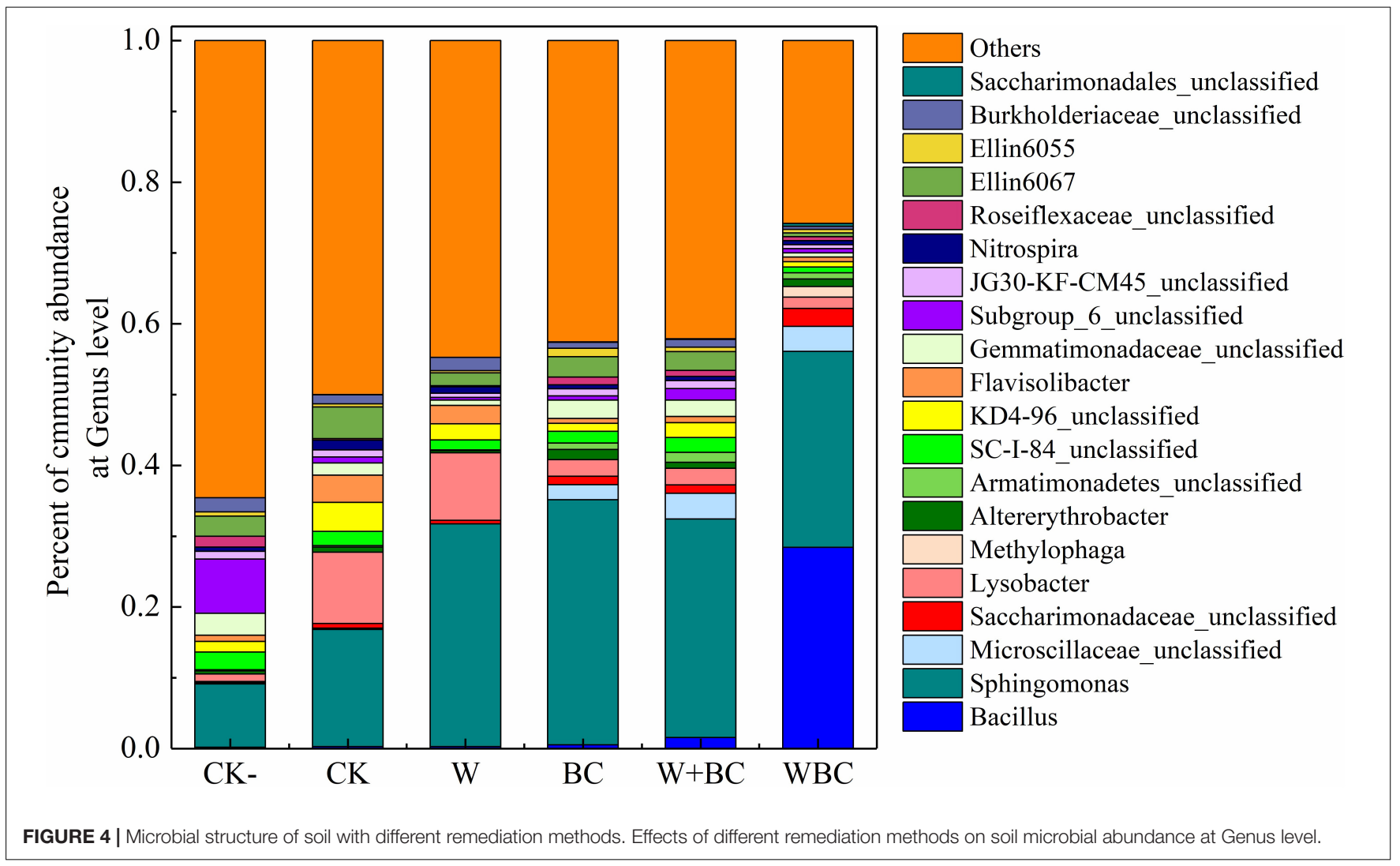


A

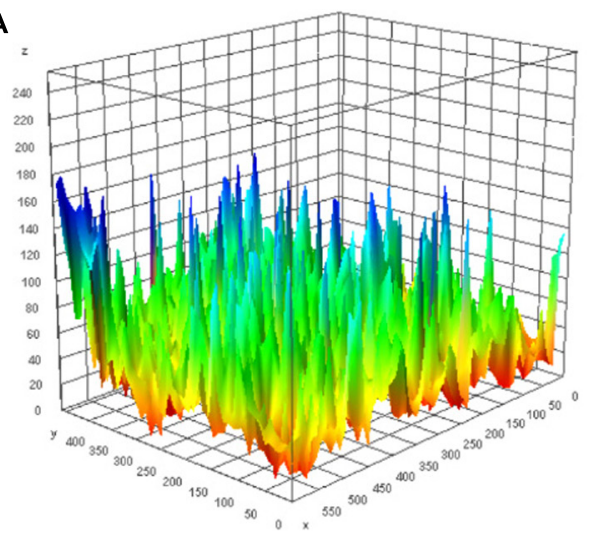

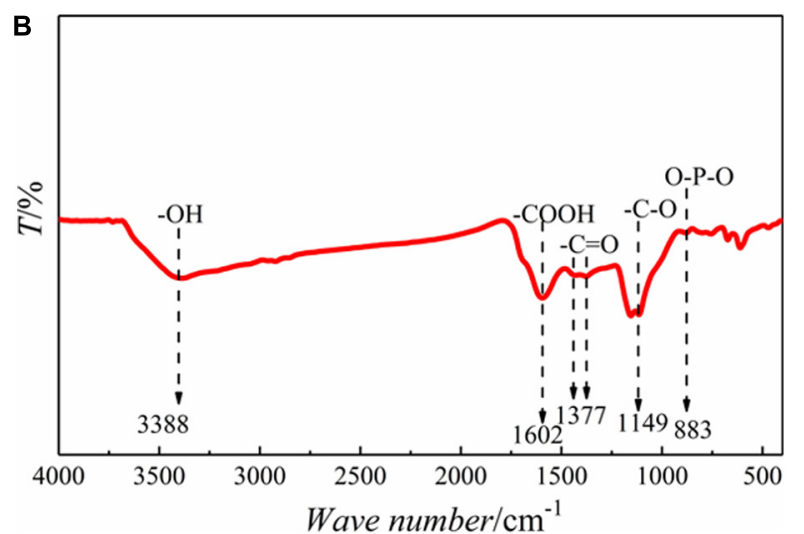

FIGURE 5 | Characteristics of biochar surface. (A) 3D Image of biochar surface. (B) FT-IR spectra.

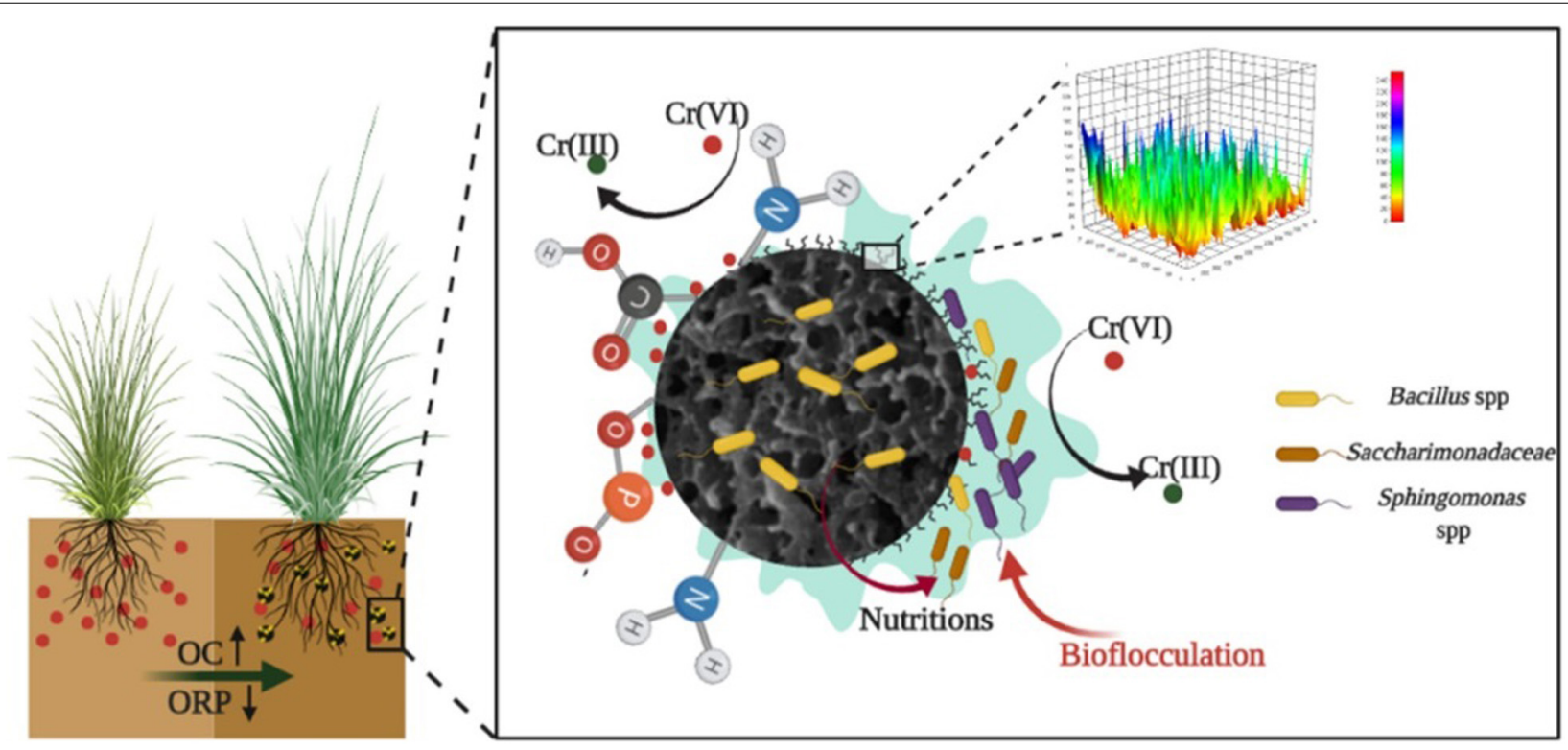

FIGURE 6 | Remediation mechanism of biochar-based Cr-reducing bacteria on Cr-contaminated soil plants.

increase nutrient retention and enhance soil biological activity. Soil structure, as well as soil moisture would be improved (Minasny and McBratney, 2018). A significant reduction in ORP might have antioxidant effects, and soil nutrients could be preserved (Manuel, 2009). Moreover, lower soil bulk density and higher CEC indicated porous and fertile characteristics of soil, and plant growth would be enhanced. Soil with microbial aggregates system addition obtained outstanding characteristics, which was suitable to the growth of microorganisms, plants, and other biology.

Ryegrass was selected as the representative plant grown in the Cr-contaminated soil, and the effect of the microbial aggregates system on the physiological properties of Ryegrass was further studied to evaluate the characteristics of remediated soil for plant growth. As shown in Supplementary Figure S3, Cr content of root and stem of Ryegrass in WBC were 0.55 and
$4.28 \mu \mathrm{g} \cdot \mathrm{g}^{-1}$, respectively, obviously lower than CK and other groups. Furthermore, transfer coefficient (TF) and the biological concentration factor (BCF) were calculated to explore the influence of the microbial aggregate system on the transportation and bioaccumulation of $\mathrm{Cr}$ in Ryegrass. When the soil was remediated by the microbial aggregates system, $\mathrm{TF}$ of $\mathrm{Cr}$ in Ryegrass in WBC was 0.13 , significantly lower than that of CK (0.23) (Table 2). Lower Cr content and TF led to flourishing growth of Ryegrass. As shown in Supplementary Figure S2, Ryegrass in WBC contained higher content of chlorophyll and dry weight, as well as longer root length and higher plant height. The results indicated that the microbial aggregates could significantly reduce the $\mathrm{Cr}$ absorption of Ryegrass from the root and the growth of Ryegrass was enhanced. By comparison, the soil remediated by the strain without treatment of microbial aggregates formation or only biochar could not recover the 
soil and the plants to the common states like $\mathrm{CK}^{-}$; the main reason could be mainly focused on the effect of biochar for microbial enrichment.

\section{Effects of Microbial Aggregates on the Microbial Community in Soil}

The addition of microbial aggregates for soil remediation might improve the native microbial structure, and the two types of microorganisms together enhance the remediation of $\mathrm{Cr}$ contaminated soil. As shown in Figure 4, Bacillus spp. and Sphingomonas spp. were the main microbes of soil in WBC with a relative abundance of 28.4 and $27.7 \%$ respectively. Furthermore, Saccharimonadaceae unclassified were mainly enriched in the soil of WBC with a relative abundance of $2.5 \%$ compared with other groups. The higher abundance of Bacillus spp. in soil of WBC indicated that the microbial aggregates formation on the biochar could enhance the inhabitation of exogenous microorganisms in the contaminated soil efficiently; the results were similar to those of Wang et al. (2004). On the other hand, Saccharimonadaceae was the main microbe with the function of heavy metal transformation (Zhang et al., 2020) and Sphingomonas spp. is the main flocculating bacteria and could strengthen the adhesion of functional microorganisms to biochar (Xu Y. et al., 2020). The enrichment of the two microbes in WBC indicated that the microbial aggregated system could enhance the retention of other functional microbes when Bacillus spp. were totally enriched in the system. Moreover, in the soil added with only biochar, the abundance of Sphingomonas spp. enriched more with a relevant abundance of $34.6 \%$, indicating the important role of biochar for functional microbe retention in the microbial aggregates system (WBC).

\section{Remediation Mechanism of Microbial Aggregates}

E. prolifera biochar was selected as the carrier for the immobilization of microbes. As shown in Figure 5, the biochar surface was fitted by SEM combined with ImageJ; the $R_{a}$ and $R_{q}$ of biochar was 25.23 and 32.83 , and the specific surface area of the biochar was $152.57 \mathrm{~m}^{2} \cdot \mathrm{g}^{-1}$. By comparison, the specific surface area of the biochar made from peanut shell at $350^{\circ} \mathrm{C}$ was only $10.1 \mathrm{~m}^{2} \cdot \mathrm{g}^{-1}$ (Xu X. Y. et al., 2019), indicating a rougher and more porous surface of the biochar in this study. Moreover, lots of functional groups, i.e., -COOH $\left(1600 \mathrm{~cm}^{-1}\right)$, O-P-O $\left(900 \mathrm{~cm}^{-1}\right)$, and amide I $\left(1,600 \mathrm{~cm}^{-1}\right)$, were observed on the surface of biochar by FT-IR (Chen et al., 2011). As described by Sheng et al. (2010), these functional groups could contribute to the adhesion of bacteria to solid surface and the microbial aggregate process could be augmented. Moreover, the O-containing functional groups, e.g., -C-O $\left(1,250 \mathrm{~cm}^{-1}\right)$ and $\mathrm{C}=\mathrm{O}\left(1,400 \mathrm{~cm}^{-1}\right.$ ) (Sheng et al., 2013; Jia et al., 2017), were located on the surface of the biochar, and played as the electron donor moieties of biochar for the $\mathrm{Cr}(\mathrm{VI})$ reduction (Xu X. Y. et al., 2019). These abundant functional groups on the biochar surface could enhance the aggregation of functional groups, and the rough and porous surface would provide more active sites for the inhabitation of microbes.
As shown in Figure 6, biochar could provide nutrient elements to microorganisms except for enhancing microbial aggregation on the surface area. The stable organic carbon fraction of biochar would directly increase the OC and alter the organic components in soil through physical mixing (Han et al., 2020), and porous structures of biochar can decrease soil density (Guo et al., 2020). The environment suitable for the growth of microbes was established. The functional strain was retained by biochar in the microbial aggregates system in this study, and other microbes with the function of heavy metal transformation and bioflocculation were further enriched in the system. The stable microbial system was formed in the $\mathrm{Cr}$-contaminated soil. Finally, the $\mathrm{Cr}(\mathrm{VI})$ reduction process was enhanced by the stable microbial aggregates system and the bioavailability of $\mathrm{Cr}$ decreased. The stress of $\mathrm{Cr}$ for biology in plants was remitted and high performance of the soil remediation system was finally achieved.

\section{CONCLUSION}

A Cr(VI)-reducing strain named B. cereus WHX-1 was screened from Cr-contaminated soil, and E. prolifera biochar was selected as a carrier to establish the microbial aggregates system with the strain. The microbial aggregates system could improve the physicochemical characteristics of Cr-contaminated soil obviously by increasing OC and CEC, as well as decreasing redox potential and bulk density of soil. More $\mathrm{Cr}(\mathrm{VI})$ was transformed to $\mathrm{Cr}$ (III) with residue speciation. High-throughput sequencing indicated that $B$. cereus WHX-1 could be immobilized by $E$. prolifera biochar obviously and $\mathrm{Cr}$-contaminated soil would be remediated and obviously added with the microbial aggregates system. This study would provide a new perspective for $\mathrm{Cr}$ contaminated soil remediation.

\section{DATA AVAILABILITY STATEMENT}

The raw data supporting the conclusions of this article will be made available by the authors, without undue reservation.

\section{AUTHOR CONTRIBUTIONS}

All authors listed have made a substantial, direct and intellectual contribution to the work, and approved it for publication.

\section{FUNDING}

This work was supported by the Natural Science Foundation of Shandong Province, China (ZR2019MD033).

\section{SUPPLEMENTARY MATERIAL}

The Supplementary Material for this article can be found online at: https://www.frontiersin.org/articles/10.3389/fmicb.2021. 641913/full\#supplementary-material 


\section{Supplementary Figure 1 | Growth of Ryegrass with different remediation} methods after 30 days.

Supplementary Figure 2 | The physiological characteristics of Ryegrass with different remediation methods. (A) Chlorophyll. (B) Root length. (C) Plant height. (D) Plant weight and ratio of dry weight and fresh weight.

\section{REFERENCES}

Abdelhafez, A. A., Li, J., and Abbas, M. H. H. (2014). Feasibility of biochar manufactured from organic wastes on the stabilization of heavy metals in a metal smelter contaminated soil. Chemosphere 117, 66-71. doi: 10.1016/j. chemosphere.2014.05.086

Abu Talha, M., Goswami, M., Giri, B. S., Sharma, A., Rai, B. N., and Singh, R. S. (2018). Bioremediation of congo red dye in immobilized batch and continuous packed bed bioreactor by Brevibacillus parabrevis using coconut shell biochar. Bioresour. Technol. 252, 37-43. doi: 10.1016/j.biortech.2017. 12.081

Aparicio, J. D., Lacalle, R. G., Artetxe, U., Urionabarrenetxea, E., Becerril, J. M., Polti, M. A., et al. (2021). Successful remediation of soils with mixed contamination of chromium and lindane: Integration of biological and physicochemical strategies. Environ Res. 194:110666. doi: 10.1016/j.envres.2020.110666

Chen, B. L., Chen, Z. M., and Lv, S. F. (2011). A novel magnetic biochar efficiently sorbs organic pollutants and phosphate. Bioresour. Technol. 102, 716-723. doi: 10.1016/j.biortech.2010.08.067

Chen, L. L., Ji, Y. T., Yu, Z. D., Wang, C. Q., Alvarez Pedro, J. J., Xu, X. Y., et al. (2021). Uncover the secret of granule calcification and deactivation in up-flow anaerobic sludge bed (UASB) reactor with long-term exposure to high calcium. Water Res. 189:116586. doi: 10.1016/j.watres.2020.116586

Chen, M., Li, X. M., Yang, Q., Zeng, G. M., Zhang, Y., Liao, D. X., et al. (2008). Total concentrations and speciation of metals in municipal sludge from Changsha, Zhuzhou and Xiangtan in middle-south region of China. J. Hazard. Mater. 160, 324-329. doi: 10.1016/j.jhazmat.2008.03.036

Chen, Y. Y., Lu, P. Z., Sun, P., Wei, L., Chen, G. L., and Wu, D. (2017) Interactive salt-Alkali stress and exogenous $\mathrm{Ca}^{2+}$ effects on growth and osmotic adjustment of Lolium multiflorum in a coastal estuary. Flora 229, 92-99. doi: 10.1016/j.flora.2017.02.018

Do Nascimento, J. L., De Almeida, A.-A. F., Barroso, J. P., Mangabeira, P. A. O. Ahnert, D., Sousa, A. G. R., et al. (2018). Physiological, ultrastructural, biochemical and molecular responses of young cocoa plants to the toxicity of $\mathrm{Cr}$ (III) in soil. Ecotox. Environ. Safe. 159, 272-283. doi: 10.1016/j.ecoenv.2018. 04.058

Guo, X. X., Liu, H. T., and Zhang, J. (2020). The role of biochar in organic waste composting and soil improvement: a review. Waste Manage. 102, 884-899. doi: 10.1016/j.wasman.2019.12.003

Hale, L., Luth, M., and Crowley, D. (2015). Biochar characteristics relate to its utility as an alternative soil inoculum carrier to peat and vermiculite. Soil Biol. Biochem. 81, 228-235. doi: 10.1016/j.soilbio.2014.11.023

Han, L. F., Sun, K., Yang, Y., Xia, X. H., Li, F. B., Yang, Z. F., et al. (2020). Biochar's stability and effect on the content, composition and turnover of soil organic carbon. Geoderma 364:114184. doi: 10.1016/j.geoderma.2020.114184

Healy, M. G., Ryan, P. C., Fenton, O., Peyton, D. P., Wall, D. P., and Morrison, L. (2016). Bioaccumulation of metals in ryegrass (Lolium perenne L.) following the application of lime stabilised, thermally dried and anaerobically digested sewage sludge. Ecotox. Environ. Safe. 130, 303-309. doi: 10.1016/j.ecoenv.2016.04.026

Jia, F. X., Yang, Q., Liu, X. H., Li, X. Y., Li, B. K., Zhang, L., et al. (2017). Stratification of extracellular polymeric substances (EPS) for aggregated anammox microorganisms. Environ. Sci. Technol. 51, 3260-3268. doi: 10.1021/ acs.est.6b05761

Lee, J. Y., Lee, S. H., and Park, H. D. (2016). Enrichment of specific electro-active microorganisms and enhancement of methane production by adding granular activated carbon in anaerobic reactors. Bioresour. Technol. 205, 205-212. doi: 10.1016/j.biortech.2016.01.054

Lehmann, J., Rillig, M. C., Thies, J., Masiello, C. A., Hockaday, W. C., and Crowley, D. (2011). Biochar effects on soil biota - a review. Soil Biol. Biochem. 43, 1812-1836. doi: 10.1016/j.soilbio.2011.04.022
Supplementary Figure $\mathbf{3}$ | Cr content in Ryegrass with different remediation methods.

Supplementary Figure 4 | Soil pH with different remediation methods.

Supplementary Figure 5 | The degrading curve of $\mathrm{Cr}(\mathrm{VI})$ by Bacillus cereus WHX-1.

Li, J., Luo, C., Zhang, D., Cai, X., Jiang, L., Zhao, X., et al. (2019). Diversity of the active phenanthrene degraders in PAH-polluted soil is shaped by ryegrass rhizosphere and root exudates. Soil Biol. Biochem. 128, 100-110. doi: 10.1016/j. soilbio.2018.10.008

Li, M., He, Z., Hu, Y., Hu, L., and Zhong, H. (2019). Both cell envelope and cytoplasm were the locations for chromium(VI) reduction by Bacillus sp. M6. Bioresour. Technol. 273, 130-135. doi: 10.1016/j.biortech.2018.11.006

Liu, X., Tang, J., Wang, L., Liu, Q., and Liu, R. (2019). A comparative analysis of ball-milled biochar, graphene oxide, and multi-walled carbon nanotubes with respect to toxicity induction in Streptomyces. J. Environ. Manage. 243, 308-317. doi: 10.1016/j.jenvman.2019.05.034

Luo, C. H., Lv, F., Shao, L. M., and He, P. J. (2015). Application of eco-compatible biochar in anaerobic digestion to relieve acid stress and promote the selective colonization of functional microbes. Water Res. 68, 710-718. doi: 10.1016/j. watres.2014.10.052

Manuel, J. A. (2009). Olive oil mill wastewater for soil nitrogen and carbon conservation. J. Environ. Manage. 90, 2845-2848. doi: 10.1016/j.jenvman.2009. 02.015

Minasny, B., and McBratney, A. B. (2018). Limited effect of organic matter on soil available water capacity. Eur. J. Soil Sci. 69, 39-47. doi: 10.1111/ejss.12475

Mitchell, K., Trakal, L., Sillerova, H., Avelar-González, F. J., Guerrero-Barrera, A. L., Hough, R., et al. (2018). Mobility of As, Cr and Cu in a contaminated grassland soil in response to diverse organic amendments; a sequential column leaching experiment. Appl. Geochem. 88, 95-102.

Nautiyal, P., Subramanian, K. A., and Dastidar, M. G. (2016). Adsorptive removal of dye using biochar derived from residual algae after in-situ transesterification: alternate use of waste of biodiesel industry. J. Environ. Manage. 182, 187-197. doi: 10.1016/j.jenvman.2016.07.063

Prathibha, V., Karthika, S., Cyriac, J., Sudarasanakumar, C., and Unnikrishnan, N. V. (2011). Synthesis of pure anatase $\mathrm{TiO}_{2}$ nanocrystals in $\mathrm{SiO}_{2}$ host and the determination of crystal planes by ImageJ. Mater. Lett. 65, 664-666. doi: 10.1016/j.matlet.2010.11.062

Rikmann, E., Zekker, I., Tomingas, M., Tenno, T., Loorits, L., Vabamäe, P., et al. (2016). Sulfate-reducing anammox for sulfate and nitrogen containing wastewaters. Desalin. Water Treat. 57, 3132-3141. doi: 10.1080/19443994.2014. 984339

Sheng, G. P., Xu, J., Luo, H. W., Li, W. W., Li, W. H., Yu, H. Q., et al. (2013). Thermodynamic analysis on the binding of heavy metals onto extracellular polymeric substances (EPS) of activated sludge. Water Res. 47, 607-614. doi: 10.1016/j.watres.2012.10.037

Sheng, G. P., Yu, H. Q., and Li, X. Y. (2010). Extracellular polymeric substances (EPS) of microbial aggregates in biological wastewater treatment systems: a review. Biotechnol. Adv. 28, 882-894. doi: 10.1016/j.biotechadv.2010.08.001

Siedt, M., Schäffer, A., Smith, K. E. C., Nabel, M., Roß-Nickoll, M., and van Dongen, J. T. (2021). Comparing straw, compost, and biochar regarding their suitability as agricultural soil amendments to affect soil structure, nutrient leaching, microbial communities, and the fate of pesticides. Sci. Total Environ. 751:141607. doi: 10.1016/j.scitotenv.2020.141607

Sidhu, G. P. S., Singh, H. P., Batish, D. R., and Kohli, R. K. (2017). Tolerance and hyperaccumulation of cadmium by a wild, unpalatable herb Coronopus didymus (L.) Sm. (Brassicaceae). Ecotox. Environ. Safe. 135, 209-215. doi: 10. 1016/j.ecoenv.2016.10.001

Sun, D. Q., Lan, Y., Xu, E. G., Meng, J., and Chen, W. F. (2016). Biochar as a novel niche for culturing microbial communities in composting. Waste Manage. 54, 93-100. doi: 10.1016/j.wasman.2016.05.004

Tan, H., Wang, C., Li, H., Peng, D. H., Zeng, C. T., and Xu, H. (2020a). Remediation of hexavalent chromium contaminated soil by nano-FeS coated humic acid complex in combination with Cr-resistant microflora. Chemosphere 242:125251. doi: 10.1016/j.chemosphere.2019.125251 
Tan, H., Wang, C., Zeng, G. Q., Luo, Y., Li, H., and Xu, H. (2020b). Bioreduction and biosorption of $\mathrm{Cr}(\mathrm{VI})$ by a novel Bacillus sp. CRB-B1 strain. J. Hazard Mater. 386:121628. doi: 10.1016/j.jhazmat.2019.121628

Tsui, T. H., Ekama, G. A., and Chen, G. H. (2018). Quantitative characterization and analysis of granule transformations: role of intermittent gas sparging in a super high-rate anaerobic system. Water Res. 139, 177-186. doi: 10.1016/j. watres.2018.04.002

Wang, K., Brown, R. C., Homsy, S., Martinez, L., and Sidhu, S. S. (2013). Fast pyrolysis of microalgae remnants in a fluidized bed reactor for bio-oil and biochar production. Bioresou. Technol. 127, 494-499. doi: 10.1016/j.biortech. 2012.08.016

Wang, Y. Y., Fan, Y. Z., and Gu, J. D. (2004). Dimethyl phthalate ester degradation by two planktonic and immobilized bacterial consortia. Int. Biodeter. Biodegr. 53, 93-101.

Wu, J., Zhang, J., and Xiao, C. (2016). Focus on factors affecting pH, flow of $\mathrm{Cr}$ and transformation between $\mathrm{Cr}(\mathrm{VI})$ and $\mathrm{Cr}(\mathrm{III})$ in the soil with different electrolytes. Electrochim. Acta. 211, 652-662. doi: 10.1016/j.electacta.2016.06. 048

Wu, Y. Y., Chen, Q. J., Chen, M., Chen, J., and Wang, X. C. (2005). Salt-tolerant transgenic perennial ryegrass (Lolium perenne L.) obtained by Agrobacterium tumefaciens-mediated transformation of the vacuolar $\mathrm{Na}^{+} / \mathrm{H}^{+}$antiporter gene. Plant Sci. 169, 65-73. doi: 10.1016/j.plantsci.2005.02.030

Xia, T., Gao, X. Y., Wang, C. Q., Xu, X. Y., and Zhu, L. (2016). An enhanced anaerobic membrane bioreactor treating bamboo industry wastewater by bamboo charcoal addition: performance and microbial community analysis. Bioresour. Technol. 220, 26-33. doi: 10.1016/j.biortech.2016.08.057

Xia, X., Wu, S. J., Zhou, Z. J., and Wang, G. J. (2021). Microbial Cd(II) and Cr(VI) resistance mechanisms and application in bioremediation. J. Hazard. Mater. 401:123685. doi: 10.1016/j.jhazmat.2020.123685

Xu, T., Nan, F., Jiang, X. F., Tang, Y. L., Zeng, Y. H., Zhang, W. H., et al. (2020). Effect of soil $\mathrm{pH}$ on the transport, fractionation, and oxidation of chromium(III). Ecotox. Environ. Safe 195:110459. doi: 10.1016/j.ecoenv.2020. 110459

Xu, X. Y., Huang, H., Zhang, Y., Xu, Z. B., and Cao, X. D. (2019). Biochar as both electron donor and electron shuttle for the reduction transformation of $\mathrm{Cr}(\mathrm{VI})$ during its sorption. Environ. Pollut. 244, 423-430. doi: 10.1016/j.envpol.2018. 10.068

Xu, Y., Liu, J. Q., Cai, W. S., Feng, J. Y., Lu, Z. J., Wang, H. Z., et al. (2020). Dynamic processes in conjunction with microbial response to disclose the biochar effect on pentachlorophenol degradation under both aerobic and anaerobic conditions. J. Hazard Mater. 384:121503. doi: 10.1016/j.jhazmat.2019.121503

Xu, Z., Xu, X., Tao, X., Yao, C., Tsang, D. C. W., and Cao, X. (2019). Interaction with low molecular weight organic acids affects the electron shuttling of biochar for Cr(VI) reduction. J. Hazard Mater. 378:120705. doi: 10.1016/j.jhazmat.2019.05. 098

Yang, X., Ng, W., Wong, B. S. E., Baeg, G. H., Wang, C. H., and Ok, Y. S. (2019). Characterization and ecotoxicological investigation of biochar produced via slow pyrolysis: effect of feedstock composition and pyrolysis conditions. J. Hazard Mater. 365, 178-185. doi: 10.1016/j.jhazmat.2018.10.047

Yao, Y., Hu, L., Li, S., Zeng, Q., Zhong, H., and He, Z. (2020). Exploration on the bioreduction mechanisms of $\mathrm{Cr}(\mathrm{VI})$ and $\mathrm{Hg}(\mathrm{II})$ by a newly isolated bacterial strain Pseudomonas umsongensis CY-1. Ecotox. Environ. Safe. 201:110850. doi: 10.1016/j.ecoenv.2020.110850

Yin, W. J., Guo, Z. Z., Zhao, C. C., and Xu, J. T. (2019). Removal of Cr(VI) from aqueous media by biochar derived from mixture biomass precursors of Acorus calamus Linn. and feather waste. J. Anal. Appl. Pyrolysis. 140, 86-96. doi: 10.1016/j.jaap.2019.04.024

Yu, K. L., Lau, B. F., Show, P. L., Ong, H. C., Ling, T. C., Chen, W. H., et al. (2017). Recent developments on algal biochar production and characterization. Bioresour. Technol. 246, 2-11. doi: 10.1016/j.biortech.2017. 08.009

Yuan, X. Z., Huang, H. J., Zeng, G. M., Li, H., Wang, J. Y., Zhou, C. F., et al. (2011). Total concentrations and chemical speciation of heavy metals in liquefaction residues of sewage sludge. Bioresou. Technol. 102, 4104-4110. doi: 10.1016/j. biortech.2010.12.055

Zeng, Q., Hu, Y. T., Yang, Y. R., Hu, L., Zhong, H., and He, Z. G. (2019). Cell envelop is the key site for $\mathrm{Cr}(\mathrm{VI})$ reduction by Oceanobacillus oncorhynchi W4, a newly isolated $\mathrm{Cr}(\mathrm{VI})$ reducing bacterium. J. Hazard Mater. 369, 149-155. doi: 10.1016/j.jhazmat.2019.01.031

Zhang, R. H., Li, Z. G., Liu, X. D., Wang, B. C., Zhou, G. L., Huang, X. X., et al. (2017). Immobilization and bioavailability of heavy metals in greenhouse soils amended with rice straw-derived biochar. Ecol. Eng. 98, 183-188. doi: 10.1016/ j.ecoleng.2016.10.057

Zhang, Z. C., Cao, H. Y., Song, N., Zhang, L. X., Cao, Y. G., and Tai, J. D. (2020). Long-term hexavalent chromium exposure facilitates colorectal cancer in mice associated with changes in gut microbiota composition. Food Chem. Toxicol. 138:111237. doi: 10.1016/j.fct.2020.11 1237

Zhou, J. M., Chen, H. L., Thring, R. W., and Arocena, J. M. (2019). Chemical pretreatment of rice straw biochar: effect on biochar properties and hexavalent chromium adsorption. Int. J. Environ. Res. 13, 91-105. doi: 10.1007/s41742018-0156- 1

Conflict of Interest: The authors declare that the research was conducted in the absence of any commercial or financial relationships that could be construed as a potential conflict of interest.

Copyright ( 12021 Chen, Wu, Sun, Liu, Qiao, Zhang and Zhang. This is an openaccess article distributed under the terms of the Creative Commons Attribution License (CC BY). The use, distribution or reproduction in other forums is permitted, provided the original author(s) and the copyright owner(s) are credited and that the original publication in this journal is cited, in accordance with accepted academic practice. No use, distribution or reproduction is permitted which does not comply with these terms. 